\title{
A short review on the delivery of breast anticancer drug tamoxifen and its metabolites by serum proteins
}

\begin{abstract}
The loading of tamoxifen (Tam), 4-hydroxytamoxifen (4-OH-Tam) and endoxifen (End) by carrier proteins, human serum albumin (HSA) and bovine serum albumin (BSA) was reviewed in aqueous solution at physiological $\mathrm{pH}$. The binding study is directly related to the conjugation of tamoxifen and its metabolites with serum proteins. Tamoxifen and its metabolites bind serum proteins via hydrophobic, hydrophilic and $\mathrm{H}$-bonding contacts. The loading efficacy (LE) was $45-52 \%$ for drug-protein conjugates. Modeling showed the presence of $\mathrm{H}$-bonding, which stabilized drug-protein complexation with the free binding energy of -11.79 to $-11.25 \mathrm{Kcal} / \mathrm{mol}$ for drug-HSA and -13.79 to $-12.72 \mathrm{Kcal} / \mathrm{mol}$ for drugBSA conjugates. Drug conjugation induced major perturbations on the conformation of serum proteins. Our studies indicate that serum proteins can transport tamoxifen and its metabolites to target tissues in the human body.
\end{abstract}

Keywords: Tamoxifen, Serum protein, Delivery, Loading efficacy, Spectroscopy, Modeling
Volume 4 Issue 2 - 2016

\section{Bourassa P,' Thomas TJ, ${ }^{2}$ Tajmir Riahi HA'}

'Department of Chemistry-Biochemistry and Physics, University of Quebec at Trois-Rivieres, Canada

${ }^{2}$ Department of Medicine, Rutgers Robert Wood Johnson

Medical School, USA

Correspondence: Tajmir Riahi HA, Department of ChemistryBiochemistry and Physics, University of Quebec at TroisRivieres, CP 500, Trois-Rivieres (Quebec), G9A 5H7, Canada, Tel 819-376-50II, Fax 819-376-5084 Email tammiri@uqtr.ca

Received: July 04, 2016 | Published: August 24, 2016
Abbreviations:HSA, Human Serum Albumin; BSA, Bovine Serum Albumin; Tam, Tamoxifen; 4-OH-Tam, 4-Hydroxy Tamoxifen; End, Endoxifen; FTIR, Fourier TransformInfrared

\section{Introduction}

Due to the poor solubility of tamoxifen and its metabolites in aqueous solution, delivery of these anticancer drugs is a major challenge in breast cancer therapeutics. Serum albumins are emerging as versatile protein carriers for drug delivery and for improving the pharmacokinetic profile of peptide or protein-based drugs.$^{1-3}$ Serum proteins contain multiple binding sites with different affinity and can transport drugs, fatty acids, steroid hormones and many other lipophilic compounds ${ }^{4-12}$ In order to evaluate the potential application of serum proteins in the delivery of tamoxifen and its metabolites in vivo, it was of interest to compare the conjugation of these drugs with serum proteins in aqueous solution. A recent study showed that the anticancer drug, doxorubicin could be transported by serum proteins.${ }^{13}$ Carrier proteins such as HSA and BSA show different hydrophobicity. ${ }^{14}$ and exhibit different affinity towards drug interactions.

Tamoxifen is an antitumor drug that has been in worldwide use for the treatment of estrogen receptor (ER)-positive breast cancer for over 30 years and has been used in both the metastatic and adjuvant settings. Tamoxifen suffers from low solubility and low selectivity, and thus the long-term usage of drug exposes patients at increased risk of having uterine malignancies.$^{15,16}$ In the clinical development of tamoxifen, it became clear that tamoxifen underwent metabolism to 4-hydroxytamoxifen and endoxifen (Scheme 1), and these metabolites exerted tamoxifen's drug action. Tamoxifen exerts its action as a breast cancer drug/chemoprevention agent by antagonizing the action of estradiol, by its binding to the ligand binding domain of ER $\alpha$ and provoking a conformational state of the protein that is incapable of binding to the estrogen receptor. In addition to its anti-estrogenic action, tamoxifen and its metabolites form adducts with DNA and hepatic toxicity is found in animal models.${ }^{17}$ Loading of tamoxifen and its metabolites with serum proteins increases the solubility of the drug and improves its tissue-specific targeting as well as provides a tool for the sustained release of the drug ${ }^{17-20}$

In this review we compared the conjugation of tamoxifen and its metabolites 4-hydroxytamoxifen and endoxifen with human and bovine serum albumins, using the results of multiple spectroscopic methods, and docking studies. This review provides useful information for the use of serum proteins in delivery of tamoxifen and its metabolites.

\section{Experimental}

\section{Molecular modeling}

The structure of free HSA (PDB id:1AO6, chain A) obtained by $\mathrm{X}$-ray crystallography was used as a template. ${ }^{21}$ The structure of BSA was predicted by automated homology modeling using SWISSMODEL Workspace from the amino acid sequence NP-851335. ${ }^{22}$ ${ }^{24}$ The two proteins share $78.1 \%$ of sequence identity, which is sufficient to obtain reliable sequence alignment. The docking studies were performed with Argus Lab 4.0.1software (Mark A. Thompson, Planaria Software LLC, Seattle, WA, http://www.arguslab.com). Three dimensional structures of tamoxifen and its metabolites were obtained from PM3 semi-empirical calculations, using Chem3D Ultra $6.0 .^{25,26}$

\section{Fluorescence spectroscopy}

Fluorimetric experiments were carried out on a Varian Cary Eclipse. Solutions containing drug 1 to $80 \mu \mathrm{M}$ in Tris- $\mathrm{HCl}(\mathrm{pH}$ $=7.4$ ) were prepared at room temperature and maintained at $24{ }^{\circ} \mathrm{C}$. Solutions of HSA and BSA $20 \mu \mathrm{M}$ in $10 \mathrm{mM}$ Tris- $\mathrm{HCl}(\mathrm{pH}=7.4)$ were also prepared at $24{ }^{\circ} \mathrm{C}$. The fluorescence spectra were recorded at excitation $=280 \mathrm{~nm}$ and emission from 287 to $500 \mathrm{~nm}$. The intensity at $347 \mathrm{~nm}$ (tryptophan) was used to calculate the binding constant (K) as reported.$^{25,26}$

\section{FTIR spectroscopy}

Infrared spectra were recorded on a FTIR spectrometer (Impact 420 model), equipped with deuterated triglycine sulphate (DTGS) detector and $\mathrm{KBr}$ beam splitter, using $\mathrm{AgBr}$ windows. Solution of 
drug was added drop wise to the protein solution with constant stirring to ensure the formation of homogeneous solution and to reach the target drug concentrations of 15,30 and $60 \mu \mathrm{M}$ with a final protein concentration of $60 \mu \mathrm{M}$. Spectra were collected after $2 \mathrm{~h}$ incubation of HSA or BSA with drug solution at room temperature, using hydrated films. Interferograms were accumulated over the spectral range $4000-600 \mathrm{~cm}^{-1}$ with a nominal resolution of $2 \mathrm{~cm}^{-1}$ and 100 scans. The difference spectra [(protein solution+ drug solution)-(protein solution)] were generated using water combination mode around 2300 $\mathrm{cm}^{-1}$, as standard.$^{27}$

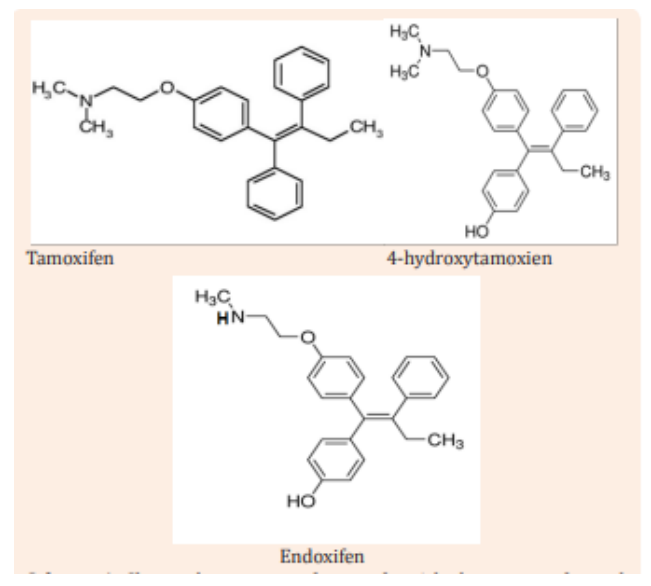

Scheme I Chemical structures of tamoxifen, 4-hydroxytamoxifen and endoxifen.

\section{Analysis of protein secondary structure}

Analysis of the secondary structures of HSA and BSA and their drug complexes were carried out as reported. ${ }^{28,29}$ The curve-fitting analysis was performed using the GRAMS/AI Version 7.01 software of the Galactic Industries Corporation.

\section{Results and Discussion}

\section{Location of drug binding sites on HSA and BSA by docking}

Docking results for tamoxifen and its metabolites conjugated with HSA and BSA are presented in Figure 1 and Table 1. In drugHSA conjugates, tamoxifen is surrounded by Arg-145, Arg-186, Glu-141, Gly-189, Ile-142, Leu-115, Leu-154, Leu-182, Leu-185, Lys-137, Lys-190, Met-123, Phe-134, Phe-149, Phe-157, Tyr-138 and within the hydrogen bonding distance of *Tyr-161 (Figure 1A). 4-Hydroxytamoxifen is located next to Arg-117, Arg-145, Arg-186, Glu-141, His-146, Ile-142, Leu-115, Leu-182, Leu-185, Lys-137, Met-123, Phe-134, Phe-165, Tyr-138 and Tyr-161 and H-bonding to *Leu-186 (Figure 1B \& Table 1). Endoxifen is located in the vicinity of Arg-145, Arg-186, Glu-141, Ile-142, Leu-115, Leu-182, Leu-185, Lys-137, Met-123, Phe-134, Phe-165, Tyr-138 and Tyr-161 with H-bonding distance of *Leu-182, *Leu-185 and *Ile-142 residues (Figure 1C \& Table 1) The free binding energy $(\Delta G)$ shows the stability of the complexes formed: 4-hydroxytamoxifen $>$ endoxifen $>$ tamoxifen (Table 1). In the drug-BSA adducts, tamoxifen is surrounded by Asp118, Asp-129, Cys-123, Glu-130, Leu-138, Lys-116, Phe-36, Phe126, Phe-133, Pro-117, Trp-134 and Tyr-137 (Figure1D \& Table 1). 4-Hydroxytamoxifen is located next to Asp-118, Asp-129, Cys-123, Glu-130, Leu-122, Phe-36, Phe-126, Phe-133, Trp-134 and Tyr-137 with hydrogen bonding network with residue *Cys-122 and *Leu-122 (Figure 1E) Finally, endoxifen is in the vicinity of Asp-37, Gly-135, Leu-138, Phe-36, Phe-126, Phe-133, Pro-35, Trp-134, Tyr-137 with h-bonding distance of the *Asp-37, *Leu-138 and $*$ Trp-134 residues (Figure 1F \& Table 1).

\section{Binding parameters of drug- protein conjugation by fluorescence spectroscopy}

Tryptophan emission dominates both HSA and BSA fluorescence spectra in the UV region. ${ }^{30-32}$ The decrease of fluorescence intensity of HSA and BSA has been monitored at $347 \mathrm{~nm}$ for tamoxifen and its metabolites upon protein conjugation (Figure 2). Figure 2 shows the effect of tamoxifen and its metabolites on HSA, and BSA fluorescence intensity. The fluorescence intensity of HSA and BSA markedly decreased as the drug concentration increased, due to the complex formation between drug and HSA and BSA (Figure 2). The protein undergoes conformational changes in the presence of tamoxifen and its metabolites, such as observed with the tryptophan residues (fluorophore) inside become more exposed to the surface after drug-protein conjugates. Assuming that the observed changes in fluorescence come from the interaction between drug and protein, the quenching constant can be taken as the binding constant of the complex formation. As it is shown in Table 2, drugs form strong conjugates with HSA, BSA. It seems that protein hydrophobicity did not play a major role in drug complex formation. HSA is less hydrophobic than BSA. ${ }^{14}$ However, HSA with more hydrophilic character forms more stable complexes than BSA. ${ }^{25,26}$ This is not consistent with docking results that showed BSA forms more stable drug conjugates (Tables $1 \& 2)$.

The plot of $F 0 / F$ versus $\mathrm{Q}$ is linear for drug-HSA and drug-BSA conjugates indicating that the quenching is mainly static in these drugprotein complexes. ${ }^{31}$ The $K q$ was estimated according to the Stern-

$$
F_{0} / \mathrm{F}=1+\mathrm{K}_{s v}[\mathrm{Q}]=1+K_{q} t_{0}[\mathrm{Q}]
$$

\section{Volmer equation}

I where $F_{0}$ and $F$ are the fluorescence intensities in the absence and presence of quencher, $[Q]$ is the quencher concentration and $K$ is the Stern-Volmer quenching constant, which that can be estimated from $K_{\mathrm{D}}=k q t_{0}$; where $k Q$ is the bimolecular quenching rate constant and $t_{0}$ is the lifetime of the fluorophore in the absence of quencher, 5.9 ns for BSA and $5.6 \mathrm{~ns}$ for HAS. ${ }^{30}$ Since $K_{q}$ values are much greater than the maximum collisional quenching constant (Table 2), thus the static quenching is dominant in these drug-protein conjugates. ${ }^{33}$

\section{Figure 1}

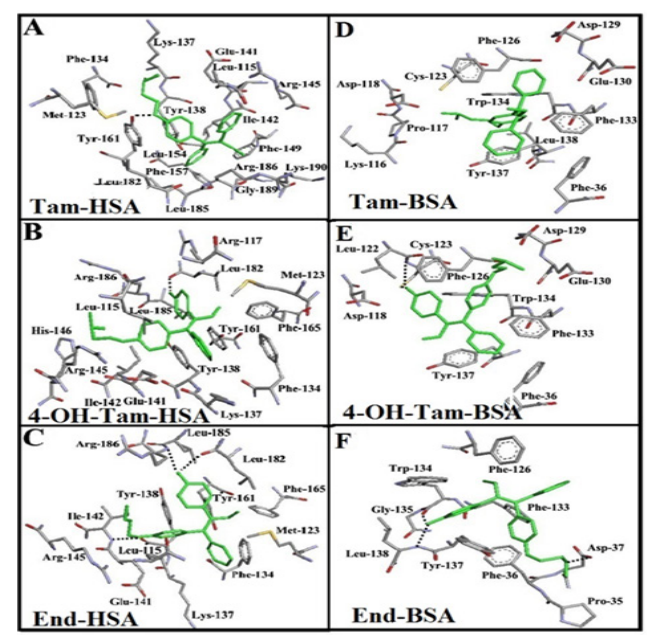

Figure I Best docked conformations of Tam-HSA (A), 4-Hydroxytam-HSA (B), End-HSA (C), Tam-BSA (D), 4-Hydroxytam-BSA (E) and End-BSA (F). 
Table I Amino acid residues involved in drug-HSA and drug-BSA conjugates with the free binding energy for the best selected docking positions

\begin{tabular}{|c|c|c|}
\hline Complex & Residues Involved in the Interaction & $\Delta \mathbf{G}$ binding (kcal/mol) \\
\hline Tamoxifen - HSA & 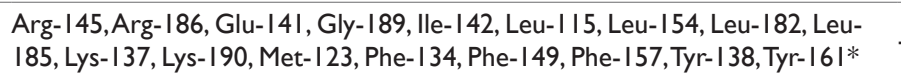 & -11.25 \\
\hline 4-Hydroxytamoxifen - HSA & 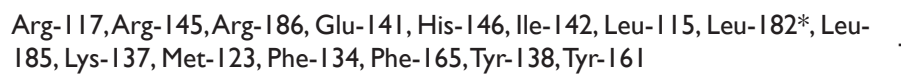 & -11.79 \\
\hline Endoxifen - HSA & 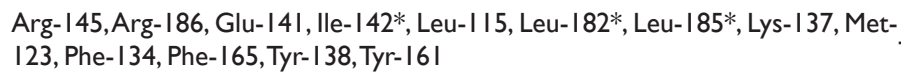 & -11.28 \\
\hline Tamoxifen - BSA & 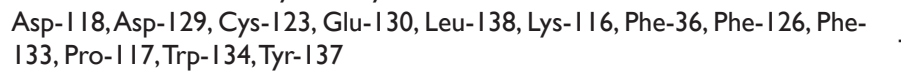 & -13.47 \\
\hline 4-Hydroxytamoxifen - BSA & $\begin{array}{l}\text { Asp-I 18, Asp-129, Cys-123*, Glu-130, Leu-122*, Phe-36, Phe- I 26, Phe-133, } \\
\text { Trp-134, Tyr-137 }\end{array}$ & -13.79 \\
\hline Endoxifen - BSA & $\begin{array}{l}\text { Asp-37*, Gly-135, Leu-138*, Phe-36, Phe- I26, Phe-133, Pro-35, Trp- I34*, Tyr- } \\
\text { I37 }\end{array}$ & -12.72 \\
\hline
\end{tabular}

*Hydrogen bonding with this amino acid residue.

The loading efficacy for drug protein conjugates was determined as reported. ${ }^{33}$

$$
\% \text { Efficiency }=\frac{\text { initial fluorescence intensity }- \text { final fluorescence intensity }}{\text { initial fluorescence intensity }} \times 100
$$

The loading efficacy was estimated $45-52 \%$ for these drug-protein conjugates (Table 2).

\section{Binding analysis of drug-protein conjugates by FTIR spectroscopy}

The conjugation of tamoxifen and its metabolites with BSA and HSA was characterized by infrared spectroscopy and its derivative methods. Drug-protein interactions alter protein conformation and induce spectral change for protein amide I band at 1659-1657 $\mathrm{cm}^{-1}$ (mainly $\mathrm{C}=\mathrm{O}$ stretch) and amide II band at $1546-1545 \mathrm{~cm}^{-1}(\mathrm{C}-\mathrm{N}$ stretching coupled with $\mathrm{N}-\mathrm{H}$ bending modes).$^{34}$ The intensity variations of protein amide I and amide II bands obtained by difference spectra [(protein solution + drug solution $)-($ protein solution $)]$ are shown in Figure 3.

At low drug concentration $(15 \mu \mathrm{M})$, while protein amide I and amide II showed no major shifting, while a major intensity changes were observed for the protein amide I and amide II, in the difference spectra of the drug-HSA and drug-BSA conjugates (Figure 3A \& 3B) diffs $0.125 \mathrm{mM}$. The positive features due to the increase in intensity of amide I and amide II bands are located in the difference spectra at 1655 and $1546 \mathrm{~cm}^{-1}$ (Tam-HSA), at 1656 and $1546 \mathrm{~cm}^{-1}$ (4hydroxy-Tam-HSA) and at 1653 and $1541 \mathrm{~cm}^{-1}$ (End-HSA) (Figure 3A) diffs $0.125 \mathrm{mM}$. Similarly, for drug-BSA adducts, positive feature were observed at 1655 and $1542 \mathrm{~cm}^{-1}$ (Tam-BSA), at 1653 and 1551 $\mathrm{cm}^{-1}$ (4-hydroxy-Tam-BSA) at 1655 and $1542 \mathrm{~cm}^{-1}$ (End-BSA) (Figure 3B) diffs $0.125 \mathrm{mM}$. However, as drug concentration increased $(0.5$ $\mathrm{mM})$, decreases in intensity of protein amide I and amide II were observed with negative features at 1655 and $1541 \mathrm{~cm}^{-1}$ (Tam-HSA), at 1664 and $1526 \mathrm{~cm}^{-1}$ (4-hydroxy-Tam-HSA) and at 1663 and 1505 $\mathrm{cm}^{-1}$ (End-HSA) (Figure 3A) diffs $0.125 \mathrm{mM}$. Similarly, for drug-BSA adducts, positive features were observed at 1653 and $1549 \mathrm{~cm}^{-1}$ (TamBSA), at 1661 and $1546 \mathrm{~cm}^{-1}$ (4-hydroxy-Tam-BSA) at 1663 and 1548 $\mathrm{cm}^{-1}$ (End-BSA) (Figure 3B) diffs $0.125 \mathrm{mM}$. The spectral variations observed are due changes in the intensity of the amide I and amide II band, upon drug binding with protein $\mathrm{C}-\mathrm{O}, \mathrm{C}-\mathrm{N}$ and $\mathrm{NH}$ groups and also related to reduction of protein $\alpha$-helix contents. ${ }^{26,27}$

The secondary structures of the free HSA and BSA and their drug conjugates are shown in Figure 4. The free HSA has $57 \% \alpha$-helix $\left(1656 \mathrm{~cm}^{-1}\right), \beta$-sheet $14 \%\left(1628\right.$ and $\left.1617 \mathrm{~cm}^{-1}\right)$, turn structure 13 $\%\left(1679 \mathrm{~cm}^{-1}\right), \beta$-antiparallel $4 \%\left(1689 \mathrm{~cm}^{-1}\right)$ and random coil $12 \%$ $\left(1637 \mathrm{~cm}^{-1}\right)$ (Figure 4A). The free BSA contains $\alpha$-helix 63\% (1656 $\left.\mathrm{cm}^{-1}\right), \beta$-sheet $16 \%\left(1612\right.$ and $\left.1626 \mathrm{~cm}^{-1}\right)$, turn $12 \%\left(1678 \mathrm{~cm}^{-1}\right), \beta$ antiparallel $3 \%\left(1691 \mathrm{~cm}^{-1}\right)$ and random coil $6 \%\left(1638 \mathrm{~cm}^{-1}\right)$ (Figure 4B). Upon drug interaction, a decrease of $\alpha$-helix from $57 \%$ (free HSA) to $55-40 \%$ with an increase in random and beta-sheet structures from $14 \%$ (free HSA) to $20-17 \%$ (drug-HSA) was observed (Figure $4 A$ ). Similarly, a decrease of $\alpha$-helix from $63 \%$ (free BSA) to 47 $39 \%$ and an increase of turn and random from $6 \%$ (free BSA) to $20-10 \%$ (drug-BSA) was observed (Figure 4B). The results showed that the conformational changes occurring are more pronounced in the case of drug-BSA and drug-HSA leading to a partial protein destabilization. ${ }^{25,26}$ Similar protein conformational changes were observed for HSA and BSA in several drug complexes. ${ }^{35-41}$

\section{Conclusion and outlook}

This review provides a comparison on the binding affinity of serum proteins with tamoxifen and its metabolites. Drugs bind BSA and HSA via hydrophilic and H-bonding contacts with HSA forming more stable conjugates than BSA. 4-Hydroxytamoxifen forms stronger protein conjugates than tamoxifen and endoxifen. Drug interaction induced more perturbations of BSA than HSA conformations. The loading efficacy of tamoxifen and its metabolites with serum proteins was $45-52 \%$. Future research should be focused on the development of new and effective nanocarriers based on biodegradable and biocompatible nanomaterials for delivery of tamoxifen and its metabolites in vivo in order to use the full potential of these important breast anticancer drugs. ${ }^{42-46}$

Table 2 Binding parameters $(\mathrm{K})$ for the drug-HSA and drug-BSA conjugates with the number of bound drug molecules $(n)$ per protein molecule andloading efficacy (LE)

\begin{tabular}{|c|c|c|c|c|c|c|}
\hline Complexes & $\begin{array}{l}\text { K } \\
\text { (Stern- } \\
\text { Volmer) } \\
\left(\times 10^{4} \mathrm{M}^{-1}\right)\end{array}$ & $\begin{array}{l}\text { K } \\
\text { (McGhee } \\
\text { von Hippel) } \\
\left(\times 10^{4} \mathrm{M}^{-1}\right)\end{array}$ & $\begin{array}{l}\text { K } \\
\text { (UV- } \\
\text { Visible) } \\
\left(\times 10^{4} \mathrm{M}^{-1}\right)\end{array}$ & $\begin{array}{l}\mathrm{Kq} \\
\left(\times 10^{12} M^{-1}\right)\end{array}$ & $\mathbf{n}$ & $\%$ LE \\
\hline $\begin{array}{l}\text { Tamoxifen - HSA } \\
\text { 4- }\end{array}$ & $1.8 \pm 0.2$ & $1.5 \pm 0.4$ & $1.2 \pm 0.2$ & $3.2 \pm 0.2$ & 1.4 & 45 \\
\hline $\begin{array}{l}\text { Hydroxytamoxifen } \\
\text { - HSA }\end{array}$ & $\mathrm{nl} .8 \pm 0.4$ & $1.6 \pm 0.5$ & $1.6 \pm 0.3$ & $3.2 \pm 0.4$ & 1.8 & 50 \\
\hline Endoxifen - HSA & $2.0 \pm 0.5$ & $2.5 \pm 0.7$ & $1.7 \pm 0.3$ & $3.5 \pm 0.2$ & 1.5 & 46 \\
\hline $\begin{array}{l}\text { Tamoxifen - BSA } \\
\text { 4- }\end{array}$ & $1.9 \pm 0.2$ & $1.6 \pm 0.2$ & $1.3 \pm 0.2$ & $3.3 \pm 0.5$ & 1.1 & 50 \\
\hline $\begin{array}{l}\text { Hydroxytamoxifen } \\
\text { - BSA }\end{array}$ & $\mathrm{nl} .8 \pm 0.2$ & $1.5 \pm 0.4$ & $1.5 \pm 0.4$ & $3.1 \pm 0.2$ & 1.5 & 52 \\
\hline Endoxifen - BSA & $0.80 \pm 0.08$ & I.I \pm 0.5 & $1.2 \pm 0.5$ & $1.3 \pm 0.2$ & 1.1 & 48 \\
\hline
\end{tabular}


Figure 2

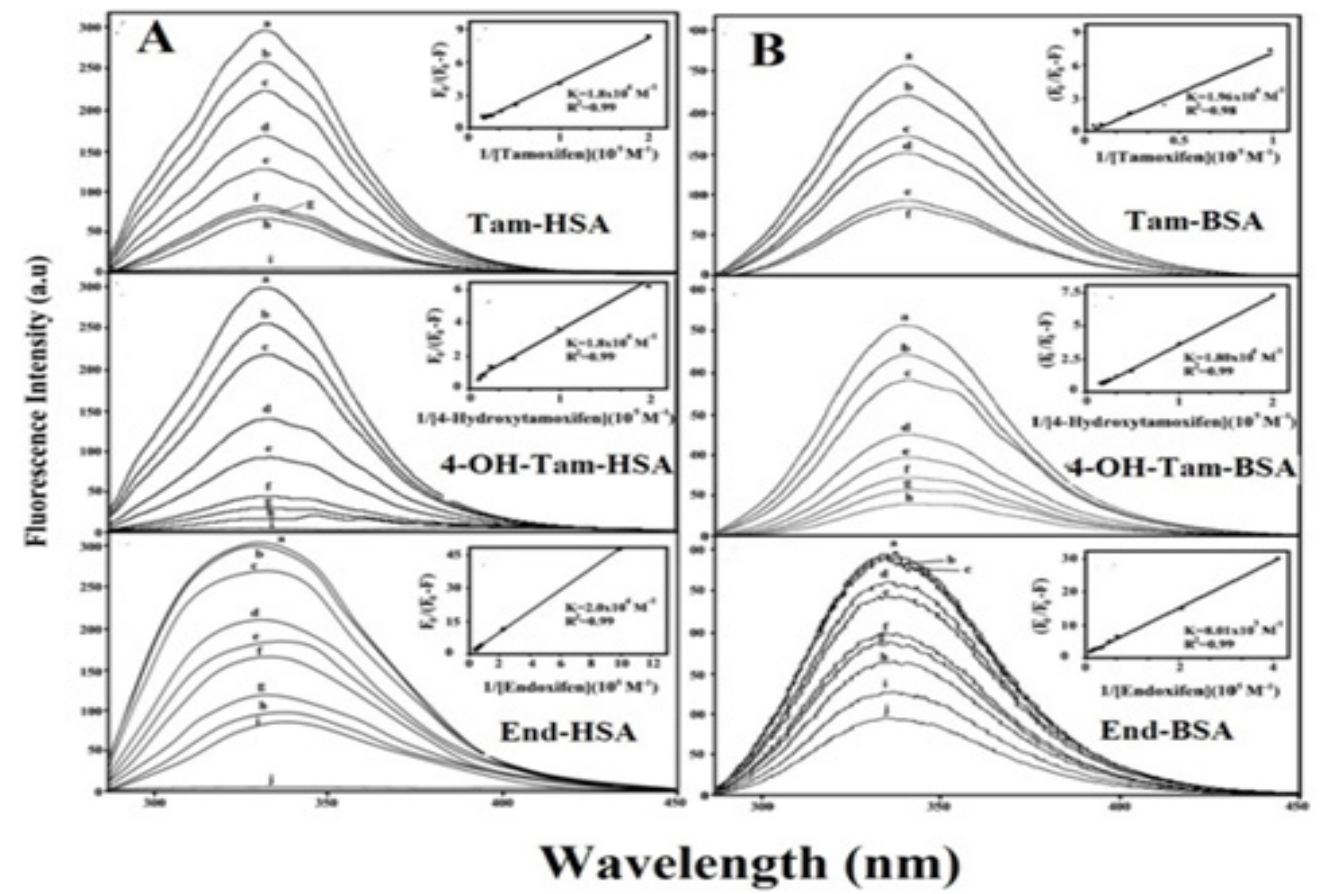

Figure 2 Fluorescence emission spectra of protein $(25 \mu \mathrm{M})$ in Tris- $\mathrm{HCl}(\mathrm{pH} 7.4)$ in the presence of tamoxifen, 4-hydroxytamoxifen and endoxifen, with $\mathrm{A})$

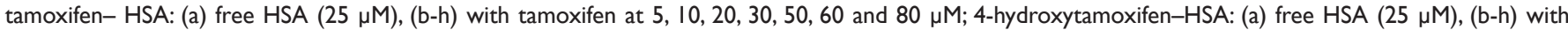
4-hydroxytamoxifen at 5, 10, 20, 30, 50, 60 and $80 \mu \mathrm{M}$ and endoxifen-HSA: (a): free HSA (25 $\mu \mathrm{M})$; (b-i) with endoxifen at I, 5, 20, 30, 40, 60, 80 and I00 $\mu \mathrm{M}$. For B) tamoxifen-BSA: (a) free BSA (25 $\mu \mathrm{M})$, (b-f) with tamoxifen at 10, 20, 60, 80 and I00 mM ; 4-hydroxytamoxifen-BSA : (a) free BSA (25 mM), (b-h) with 4-hydroxytamoxifen at 5, 10,20,40,60,80 and $100 \mathrm{mM}$ and endoxifen-BSA: (a): free BSA (25 mM); (b-j) with endoxifen at 2, 5, 10, 20, 30, 40,60, 80 and 100 mM. The plot of $I /(A-A O)$ as a function of $I / d r u g$ concentration. The binding constant $K$ being the ratio of the intercept for drug-HSA (A) and drug-BSA (B).

Figure 3
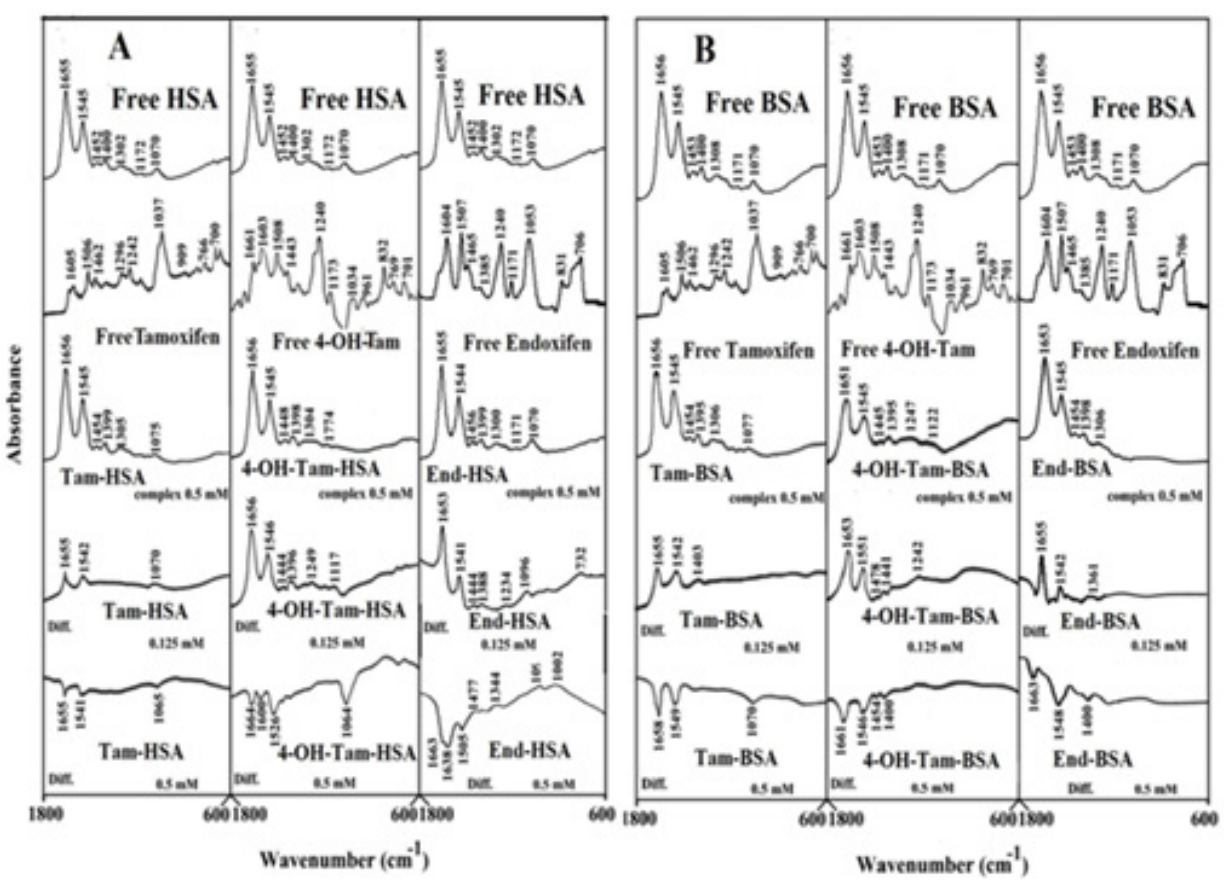

Figure 3 FTIR spectra in the region of $1800-600 \mathrm{~cm}-\mathrm{I}$ of hydrated films ( $\mathrm{pH} 7.4)$ for free HSA (A) and BSA (B) $(0.5 \mathrm{mM})$ and their drug complexes with difference spectra (diff.) (bottom two curves) obtained at different drug concentrations (indicated on the figure). 
Figure 4

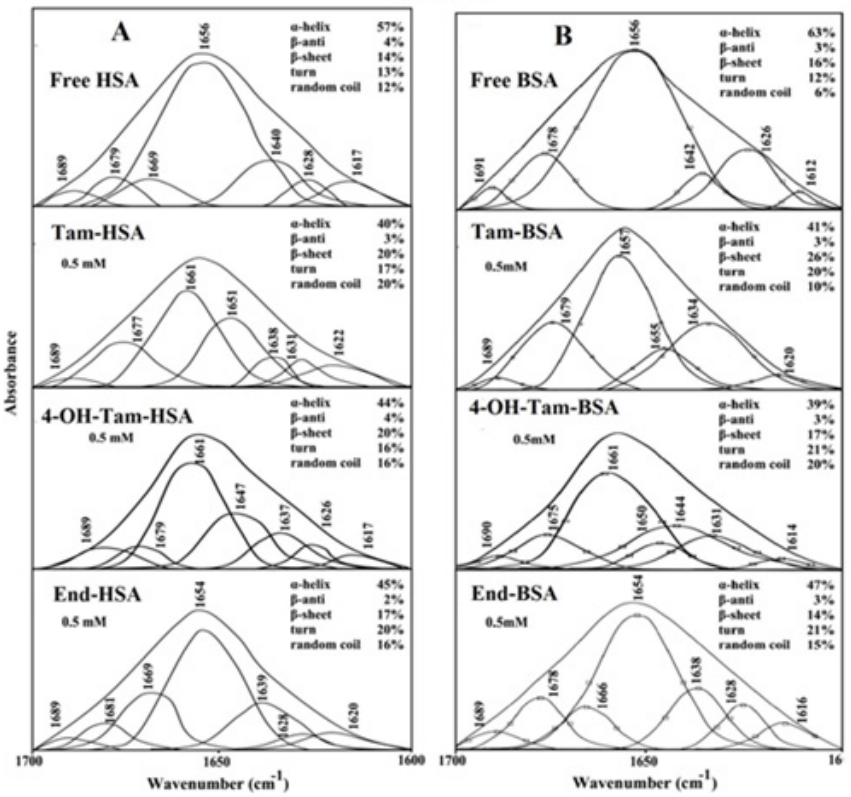

Figure 4 Second derivative resolution enhancement and curve-fitted amide I region (I700- $1600 \mathrm{~cm}-\mathrm{I})$ for free HSA (A) and free BSA (B) at $0.5 \mathrm{mM}$ and their drug conjugates at $0.5 \mathrm{mM}$ (drug).

\section{Acknowledgements}

The financial support of the Natural Sciences and Engineering Research Council of Canada (NSERC) is highly appreciated.

\section{Conflicts of interest}

None.

\section{References}

1. Elsadek B, Kratz F Impact of albumin on drug-delivery-new application on the horizon. J Control Release. 2012;157(1):4-28.

2. Kratz F, Elsadek B Clinical impact of serum proteins on drug delivery. $J$ Control Release. 2012;161(2):429-445.

3. Kratz F Albumin as a drug carrier: Design of prodrugs, drug conjugates and nanoparticles. J Control Release. 2008;132(3):171-183.

4. Yang $\mathrm{F}$, Zhang $\mathrm{Y}$, Liang $\mathrm{H}$ Interactive association of drugs binding to human serum albumin.Int J Mol Sci. 2014;15(3):3580-3595.

5. Ghuman J, Zunszain PA, Petitpas I et al. Structural basis of the drug-binding specificity of human serum albumin. $J$ Mol Biol. 2005;353(1):38-52.

6. Kratochwil NA, Huber W, Müller F, et al. Predicting plasma protein binding of drugs: a new approach. Biochem Pharmacol. 2002;64(9):1355-1374

7. Ahmed Ouameur A, Diamantoglou S, Sedaghat Herati MR, et al. An overview of drug binding to human serum albumin: Protein folding and unfolding. Cell Biochem Biophys. 2006;45:203-213.

8. Chanphai P, Vesper AR, Bekale L et al. Transporting testosterone and its dimers by serum proteins. J Photochem Photobiol B. 2015;153:173-183.

9. Bourassa P, Kanakis DC, Tarantilis P et al. Resveratrol, genistein and curcumin bind bovine serum albumin. $J$ Phys Chem $B$. 2010;114(9):3348-3354.

10. Charbonneau DM, Tajmir Riahi HA Study on the interaction of cationic lipids with bovine serum albumin. J Phys Chem B. 2010;114(2):1148-1155
11. Nsoukpoé Kossi CN, Sedaghat Herati MR, Ragi C et al. Retinol and retinoic acid bind human serum albumin: stability and structural features. Intl J Biol Macromol. 2007;40(5):484-490.

12. Mandeville JS, Froehlich E, Tajmir Riahi HA Study of curcumin and genistein interactions with human serum albumin. $J$ Pharm Biomed Anal. 2009;49(2):468-474.

13. Agudelo D, Berube G, Tajmir Riahi HA An overview on the delivery of antitumor drug doxorubicin by carrier proteins. Int J Biol Macromol. 2016;88:354-360.

14. Akdogan Y, Reichenwallner J, Hinderberger D Evidence for water-tuned structural differences in proteins: An approach emphasizing variations in local hydrophilicity. PLoS ONE. 2012;7(9):e456810.

15. Lazzeroni M, Serrano D, Dunn BK et al. Oral low dose and topical tamoxifen for breast cancer prevention:modern approaches for an old drug. Breast Cancer Research.2012;14(5):214.

16. How CW, Rasedee A, Manickam S, Rosli R Tamoxifen loaded nanostructured lipid carrier as a drug delivery system: Characterization, stability assessment and cytotoxicity. Colloids \& Surfaces B. 2013;112:393-399.

17. Vivek R, Nipun Babu V, Thangam $\mathrm{R}$ et al. $\mathrm{pH}$-responsive drug delivery of chitosan nanoparticles as tamoxifen carriers for effective anti-tumor activity in breast cancer cells. J Colloids \& Surfaces B Biointerfaces. 2013;111: 117-123

18. Jugminder SC, Amiji MM Biodegradable poly(o-caprolactone) nanoparticles for tumortargeted delivery of tamoxifen. Int J Pharm. 2002;249(1-2):127-138.

19. Sarwa KK, Suresh PK, Debnath M, et al. Tamoxifen citrate loaded ethosomes for transdermal drug delivery system: preparation and characterization Curr Drug Deliv . 2013;10(4):466-476.

20. Majda MH, Asgari D, Barar J et al. Tamoxifen Loaded folic acid armed PEGylated magnetic nanoparticles for targeted imaging and therapy of cancer. Colloids \& Surfaces B Biointerfaces. 2013;106:117-125.

21. Arnold K, Bordoli AK, Kopp L et al. The SWISS-MODEL workspace: A web-based environment for protein structure homology modeling. Bioinformatics. 2006;22(2):195-201.

22. Rost B Twilight zone of protein sequence alignment. Protein Eng. 1999;12(2):85-94.

23. Bourassa P, Hasni I, Tajmir Riahi HA Folic acid complexes with human and bovine serum albumins. Food Chem. 2011;129(3):1148-1155

24. Sugio S, Kashima A, Mochizuki S et al. Crystal structure of human serum albumin at $2.5 \mathrm{~A}^{\circ}$ resolution. Protein Eng. 1999;12(6):439-446.

25. Bourassa P, Dubeau S, Maharvi GM et al. Locating the binding sites of anticancer tamoxifen and its metabolites 4-hydroxytamoxifen and endoxifen on bovine serum albumin. Europ $J$ Med Chem. 2011;46(9):4344-4353

26. Bourassa P, Dubeau S, Maharvi GM et al. Binding of antitumor tamoxifen and its metabolites 4-hydroxytamoxifen and endoxifen to human serum albumin. Biochimie. 2011;93(7):1089-1101.

27. Dousseau F, Therrien M, Pezolet M On the spectral subtraction of water from the FT-IR spectra of aqueous solutions of proteins. Appl Spectrosc. 1989;43(3):538-542.

28. Byler DM, Susi H Examination of the secondary structure of proteins by deconvoluted FTIR spectra. Biopolymers. 1986;25(3):469-487.

29. Beauchemin R, N'soukpoe Kossi CN, Thomas TJ et al. Polyamine analogues bind human serum albumin. Biomacromolecules. 2007;8(10):3177-3183

30. Tayeh N, Rungassamy T, Albani JR Fluorescence spectral resolution of tryptophan residues in bovine and human serum albumins. J Pharm Biomed Anal. 2009;50(2):07-116. 
31. Lakowicz JR In Principles of Fluorescence Spectroscopy. (3rd edn), Springer: New York. 2006.

32. Zhang g, Que Q, Pan J, Guo J Study of the interaction between icariin and human serum albumin by fluorescence spectroscopy. J Mol Struct. 2008;881(1-3):132-138.

33. Chandra S, Dietrich S, Lang H, Bahadur D Dendrimer-doxorubicin conjugate for enhanced therapeutic effects for cancer. $J$ Mater Chem. 2011;21:5729-5737.

34. Krimm S, Bandekar J Vibrational spectroscopy and conformation of peptides, polypeptides, and proteins. Adv Protein Chem. 1986;38:181-364.

35. Tian J, Liu J, Hu Z, Chen X Binding of the scutellarin to albumin using tryptophan fluorescence quenching, CD and FT-IR spectra. Am J Immunol. 2005;1:21-23.

36. Grdadolnik J Saturation effects in FTIR spectroscopy: intensity of amide I and amide II bands in protein spectra. Acta Chim Slov. 2003;50:777-788.

37. Gokara M, Kimavathb GB, Podileb AR et al. Differential interactions and structural stability of chitosan oligomers with human serum albumin and $\alpha-1$-glycoprotein. J Biomol Struct Dyn. 2015;33(1):196-210.

38. Yeggoni DP, Gokara M, Manidhar DM et al. Binding and molecular dynamics studies of 7-hydroxycoumarin derivatives with human serum albumin and Its pharmacological importance. Mol Pharm. 2014;11(4):1117-1131.
39. Bekale L, Agudelo D, Tajmir Riahi HA Effect of polymer molecular weight on chitosan-protein interaction. Colloids \& Surfaces B Biointerfaces. 2015;125:309-317.

40. Chanphai $P$, Vesper AR, Bariyanga $J$ et al. Review on the delivery of steroids by carrier proteins. JPhotochem Photobiol B. 2016;161:184-191.

41. Bekale L, Agudelo D, Tajmir Riahi HA The role of polymer size and hydrophobic end-group in PEG-protein interaction. Colloids Surf B Biointerfaces. 2015;130:141-148.

42. Errico A Breast cancer: Tamoxifen- offering a long-term prevention option. Nat Rev Clin Oncol. 2015;12(2):66

43. $\mathrm{Hu} \mathrm{R}$, Hilakivi Clarke L, Clarke $\mathrm{R}$ Molecular mechanisms of tamoxifen- associated endometrial cancer (Review). Oncol Lett. 2015;9(4):1495-1501.

44. Thotakura N, Dadarwal M, Kumar P et al. Chitosan-stearic acid based polymeric micelles for the effective delivery of tamoxifen: Cytotoxic and pharmacokinetic evaluation. AAPS PharmSciTech. 2016

45. Agudelo D, Sanyakamdhorn S, Shoherh Nafisi Sh et al. Transporting antitumor drug tamoxifen and its metabolites, 4-hydroxytamoxifen and endoxifen by chitosan nanoparticles. PLOS ONE. 2013;8(3):e60250.

46. Sanyakamdhorn S, Bekale L, Agudelo D et al. Targete conjugation of breast anticancer drug tamoxifen and its metabolites with synthetic polymers. Colloids Surf B Biointerfaces. 2016;145:55-63. 